\title{
8
}
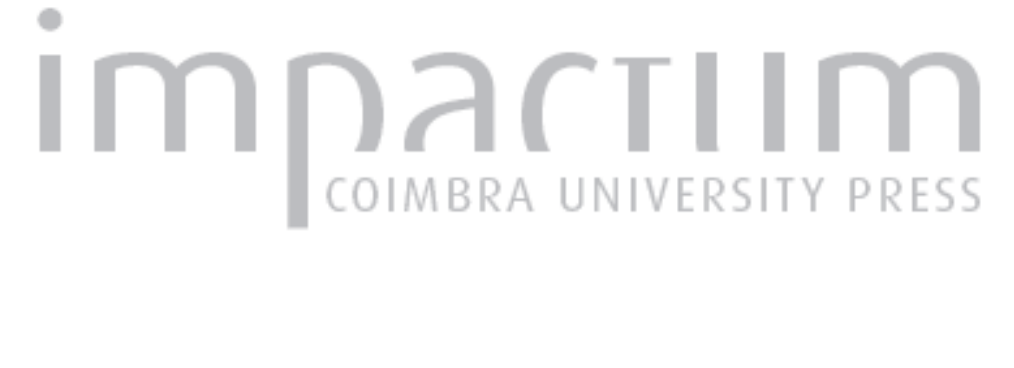
Cronotanatognose: a influência do Clima tropical na determinação do Intervalo post-
mortem
Autor(es): $\quad$ Garrido, Rodrigo Grazinoli; Naia, Maria João Teixeira
Publicado por: Universidade Católica de Petrópolis
URL persistente:
URI:http://hdl.handle.net/10316.2/33949
DOI:
DOI:http://dx.doi.org/10.14195/2175-0947_6-1_10
Accessed : $\quad$ 26-Apr-2023 10:51:13

A navegação consulta e descarregamento dos títulos inseridos nas Bibliotecas Digitais UC Digitalis, UC Pombalina e UC Impactum, pressupõem a aceitação plena e sem reservas dos Termos e Condições de Uso destas Bibliotecas Digitais, disponíveis em https://digitalis.uc.pt/pt-pt/termos.

Conforme exposto nos referidos Termos e Condições de Uso, o descarregamento de títulos de acesso restrito requer uma licença válida de autorização devendo o utilizador aceder ao(s) documento(s) a partir de um endereço de IP da instituição detentora da supramencionada licença.

Ao utilizador é apenas permitido o descarregamento para uso pessoal, pelo que o emprego do(s) título(s) descarregado(s) para outro fim, designadamente comercial, carece de autorização do respetivo autor ou editor da obra.

Na medida em que todas as obras da UC Digitalis se encontram protegidas pelo Código do Direito de Autor e Direitos Conexos e demais legislação aplicável, toda a cópia, parcial ou total, deste documento, nos casos em que é legalmente admitida, deverá conter ou fazer-se acompanhar por este aviso.

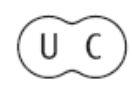



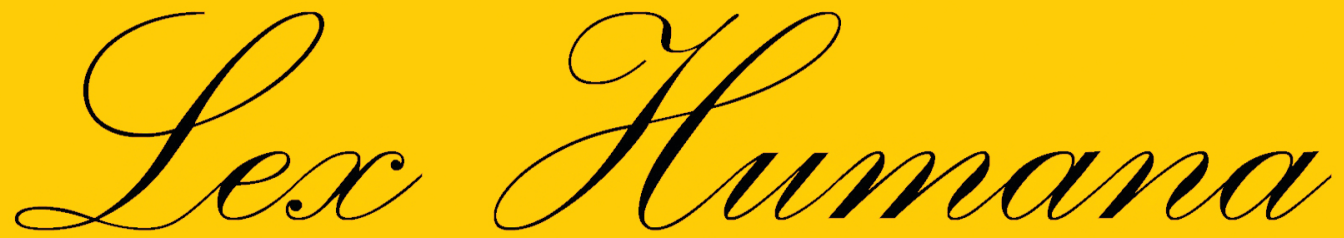

Revista do Programa de Pós-Graduação em Direito da UCP

ISSN(e) 2175-0947

Universidade Católica de Petrópolis Rua Benjamin Constant, 213 - Petrópolis - Centro CEP 25610-130

Tel: (24) 2244-4000 E-mail: lexhumana@ucp.br 


\title{
CRONOTANATOGNOSE: A INFLUÊNCIA DO CLIMA TROPICAL NA DETERMINAÇÃO DO INTERVALO POST-MORTEM
}

\section{CHRONOTHANATOGNOSIS: THE INFLUENCE OF THE TROPICAL CLIMATE IN DETERMINING THE POST-MORTEM INTERVAL*}

\author{
RODRIGO GRAZINOLI GARRIDO** \\ UNIVERSIDADE CATÓLICA DE PETRÓPOLIS, BRASIL \\ MARIA JOÃO TEIXEIRA NAIA *** \\ INSTITUTO DE CIÊNCIAS BIOMÉDICAS DE ABEL SALAZAR DA UNIVERSIDADE DO \\ PORTO, PORTUGAL
}

\begin{abstract}
Resumo: A determinação do intervalo post-mortem (IPM) é essencial para a investigação policial, pois auxilia na diagnose diferencial e na reconstrução da cena e da dinâmica do crime. Além disso, o IPM é importante para questões sucessórias. Métodos clássicos e modernos são propostos para determinar a data do decesso, mas a maioria carece de objetividade. De forma geral, os métodos são dependentes tanto de características da morte, quanto das condições ambientais, sobretudo do clima no local de encontro do cadáver. Dessa forma, por meio de pesquisa exploratória e descritiva, a partir de documentação indireta de fontes secundárias buscou-se realizar uma revisão sobre alguns métodos cronotanatognóticos. As limitações desses métodos, sobretudo quando aplicados em regiões de clima tropical foram apresentadas. Certo é que a elevada temperatura e umidade são fatores que influenciam os processos de decomposição cadavéricos e, assim, dificultam a determinação correta e consensual do IPM. Assim, há muito que se desenvolver no campo de estudo do IPM, buscando-se metodologias mais eficázes e precisas, sobretudo aplicáveis às regiões tropicais.
\end{abstract}

Palavras-chave: Tanatologia; IPM; morte violenta.

\footnotetext{
* Artigo recebido em 08/06/2014 e aprovado para publicação pelo Conselho Editorial em 30/06/2014.

** Pós-Doutorado pela Universidade Federal do Rio de Janeiro, Brasil. Doutor pela Universidade Rural do Rio de Janeiro, Brasil. Diretor do Instituto de Pesquisa e Perícias em Genética Forense do Rio de Janeiro. Professor da Universidade Católica de Petrópolis, Brasil. Currículo Lattes: http://lattes.cnpq.br/4027138006793482. E-mail: grazinoli.garrido@gmail.com.
}

*** Mestranda no Programa de Medicina Legal do Instituto de Ciências Biomédicas de Abel Salazar da Universidade do Porto, Portugal. Intercambista no Mestrado em Direito da Universidade Católica de Petrópolis, Brasil. E-mail: maria.naia19@gmail.com. 


\begin{abstract}
Post-mortem interval (PMI) determination is essential to improve police investigation. It aids differential diagnosis and the reconstruction of the scene, as well as the dynamics of crime. Furthermore, PMI is important for inheritance-related questions. Classical and modern methods are proposed to determine the date of death, but most of them lack objectivity. In general, the methods are dependent on both the characteristics of death. Moreover, the environmental conditions, especially climate at the crime scene, determines which methods fit better. In this way, through exploratory and descriptive research from indirect documentation of secondary sources we attempted to review chronothanatognosis method. It was presented limitations of these methods, especially when applied to tropical regions. It is certain that the high temperature and humidity are factors that influence the processes of cadaveric decomposition and, thus, hinder the correct and consensual determination of PMI. Thus, there is much to develop in the field of study of PMI, seeking for more effective and accurate methodologies, particularly applicable to tropical regions.
\end{abstract}

Keywords: Thanatology; PMI; violent death.

\title{
1. Introdução
}

A morte é um acontecimento inevitável, embora ocorra de forma imprevisível. $\mathrm{Na}$ maioria dos casos, quando os cadáveres são descobertos não se sabe o momento do evento fatal, o que impossibilita o início de uma boa investigação. Essa datação é muitas vezes variável e dependente de diversos fatores, tais como o modo e o local da morte e as condições ambientais onde o corpo foi encontrado. Assim, um dos principais problemas que ainda existe na perícia criminal e médico-legal é a determinação do intervalo post-mortem, principalmente nos casos onde haja suspeita de homicídio (JAFFE, 1983).

Uma vez que a maioria das vítimas de homicídios é encontrada nas primeiras 48h, torna-se extremamente importante datar o intervalo post-mortem (IPM) de uma maneira rápida e com especificidade e sensibilidade capaz de distinguir períodos neste lapso de tempo (JOHNSON e FERRIS, 2002). Contudo, apesar dos inúmeros avanços científicos e tecnológicos, a capacidade para estimar a data da morte mantém-se limitada na prática forense. Os métodos existentes apresentam uma margem de erro de $8 \mathrm{~h}$ o que dificulta tal determinação para cadáveres recentes (JOHNSON e FERRIS, 2002).

Para auxiliar a datação, os profissionais recorrem ao cruzamento de informações obtidas de diversas fontes, nomeadamente de evidências do próprio cadáver, do meio que envolve o corpo e a partir da história clínica e dos acontecimentos e atividades que o indivíduo 
desenvolvia antes de morrer (JAFFE, 1983). Na verdade, a literatura é constantemente expandida por novos métodos que buscam determinar alterações ocorridas durante o IPM, contribuindo para determinar com maior exatidão o intervalo temporal a partir da morte.

Dessa forma, por meio de pesquisa exploratória e descritiva, desenvolvida a partir de documentação indireta de fontes secundárias como livros, artigos e site, buscou-se mostrar os métodos usuais e aqueles atualmente propostos para a determinação do IPM. Além disso, propõem-se reunir o que se conhece sobre as possíveis interferências na determinação do IPM das condições ambientais, em especial das altas temperatura e umidade comuns das regiões tropicais.

\section{Cronotanatognose}

O termo cronotanatognose é constituído pelas palavras gregas kromos que significa tempo, thanatos nome do Deus grego relacionado com a morte e gnosis, conhecimento. Assim, pode-se afirmar que cronotanatognose é o conhecimento ou a determinação do tempo decorrido entre a morte e encontro do cadáver, também anteriormente referido como IPM.

Esta datação nem sempre é fácil de ser realizada, pois está demasiadamente dependente de diversos fatores. Superficialmente ela está relacionada à análise dos fenômenos cadavéricos naturais do corpo, mas como também estes são pouco objetivos e variam consoante à influência de fatores internos e externos, o resultado dessa análise, ou seja, a data provável do acontecimento é muitas vezes um valor aproximado ou até um intervalo de tempo (WOELFERT, 2003).

Os fenômenos cadavéricos dependem da atuação de fatores que podem funcionar como impulsionadores ou inibidores da decomposição, o que irá resultar num adiamento ou atraso do intervalo post-mortem. É ainda de notar que quanto maior o tempo que se demora a encontrar um corpo, ou seja, quanto maior o IPM, mais difícil se torna determinar o seu valor e, consequentemente, este será menos sensível, podendo existir uma diferença de horas, dias ou até semanas.

Em casos de morte violenta, a datação do IPM tem importância na reconstrução do modo e das circunstâncias da morte, na ligação do suspeito à(s) cena(s) do crime ou à vítima e no estabelecimento da veracidade das informações fornecidas por testemunhas. O IPM também tem aplicações na área cível, em casos de morte natural, acidental ou suicídio, por ter implicações em questões sucessórias (GREENBERG e KUNICH, 2002). 
Apesar da importância na determinação do IPM, existem poucos estudos que descrevam os efeitos climáticos na decomposição de restos mortais. Em estudo efetuado neste sentido, investigaram-se os efeitos sazonais, temperatura e pluviosidade com o índice de perda de massa de carcaças de porcos e com a duração das fases dos processos de decomposição cadavérica. Verificou-se interação significativa entre a estação do ano e o tempo que faltava para completar a putrefação: seria maior no inverno, seguido do outono, primavera e verão. A chuva e as altas temperaturas, como ocorem nas regiões tropicais do globo, incrementam tanto os índices de perda de massa, como os índices de progressão das fases de decomposição (ARCHER, 2004).

\subsection{Clima Tropical}

A linha do equador e o trópico de Capricórnio atravessam o Brasil, tornando o clima com tonalidades tropicais bem marcantes. Nessa faixa climática, a umidade é elevada devido à circulação de ventos de leste (ROSS, 2003), tal como se encontra representado na figura 1, demonstrando o exemplo da cidade do Rio de Janeiro.

O clima tropical no país caracteriza-se pela existência de temperaturas médias superiores a $18^{\circ} \mathrm{C}$ e diferenças sazonais marcadas pelo regime de pluviosidade, períodos que também regulam os regimes fluviais. Tal como nas regiões de baixas latitudes, nas quais está inserido o Brasil, ocorre um fenômeno de isotermia, isto é, a amplitude térmica anual não varia além de $6^{\circ} \mathrm{C}$, o que pode ser observado na figura 2, para o Rio de Janeiro. A elevada taxa de umidade, no território brasileiro, é também influenciada pela cobertura vegetal fechada e abundante no país (ROSS, 2003).

Apesar das características da tropicalidade se manifestarem em quase todo o país, encontram-se algumas diferenças entre regiões. No entanto, de forma geral, o clima permanece sempre com características tropicais (ROSS, 2003). 


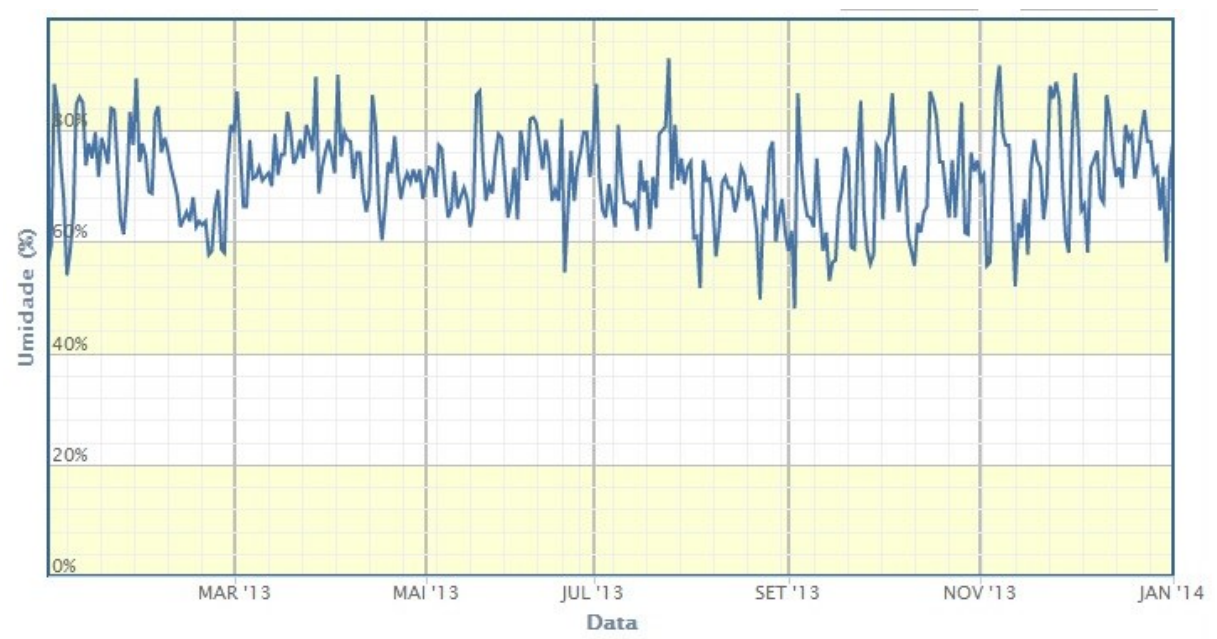

Figura 1 - Variação da umidade (\%) ao longo do ano de 2013 na cidade do Rio de Janeiro. (Fonte: INMET)

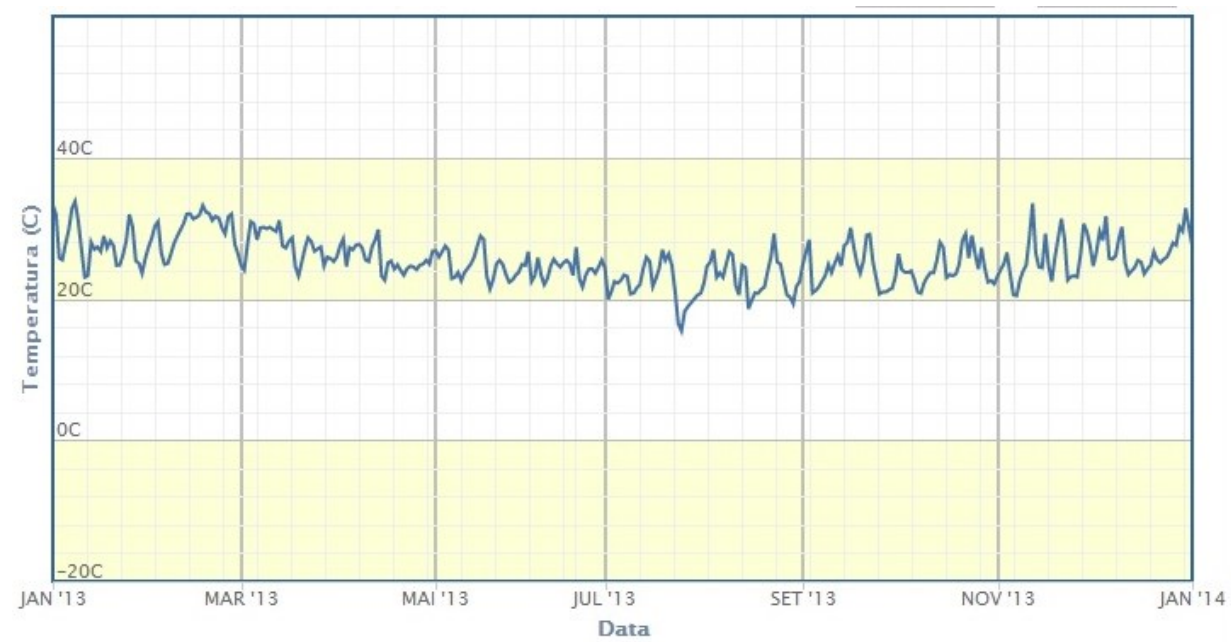

Figura 2 - Variação da temperatura $\left({ }^{\circ} \mathrm{C}\right)$ ao longo do ano 2013 na cidade do Rio de Janeiro. (Fonte: INMET)

Cada método usado atualmente para determinar o IPM é dependente das variações de temperatura e de umidade existentes no local onde o corpo foi encontrado. As elevadas temperaturas e o grande percentual de umidade característicos dos trópicos contribuem significativamente para o desenvolvimento dos fenômenos putrefativos e para a deterioração do aspeto morfológico do cadáver, o que faz com que seja fundamental manter cautela e um maior rigor na hora de determinar o IPM. Para além disso, estes fatores climáticos influenciam ainda o aparecimento de alterações macroscópicas que resultam da ação de fatores externos e internos, tais como danos peri ou post-mortem (LUCIO, 2013). 
Alguns autores afirmam que a temperatura ideal para que ocorra a decomposição do cadáver varia entre os 21 e os $38^{\circ} \mathrm{C}$, o que se enquadra nos valores médios de temperatura verificados no Brasil (Figura 2). Tal temperatura média aliada a elevados níveis de umidade incrementa mais ainda a decomposição (POUNDER, 2000).

Assim, ainda não se pode afirmar que exista um método que atenda a todos os casos, ou seja, um "método perfeito". Quando se pretende datar o evento da morte, tem de se ter em conta diversas variáveis que estão implícitas ao cadáver, mas também aquelas que estão no meio envolvente e que podem ser significativas, dando origem a resultados, por vezes, discrepantes.

\section{Métodos Cronotanatognóticos}

\subsection{Métodos Cronotanatognóticos Clássicos}

Os métodos de datação do IPM que se baseiam em avaliações subjetivas do cadáver demandam a análise e o conhecimento prévio das alterações e fenômenos que ocorrem em cada estágio após a morte. Assim, os resultados podem não ser consensuais e podem até ser adulterados involuntariamente. Isto é, dependem da experiência do profissional, das técnicas que ele usa e, ainda, de fatores externos que não são controlados, como a temperatura, a umidade e a ação de animais ou fatores inerentes ao próprio cadáver.

Estes métodos avaliam os fenômenos que se começam a verificar logo após a cessação da atividade metabólica do indivíduo, são os denominados fenômenos post-mortem. Classicamente, os fenômenos post-mortem podem ser categorizados como abióticos ou transformativos.

\subsubsection{Fenômenos cadavéricos abióticos}

Os fenômenos cadavéricos abióticos são aqueles que se tornam evidentes logo após a morte do indivíduo, ainda antes da proliferação bacteriana, e têm curta duração. São exemplos: arrefecimento corporal, aparecimento de livores de hipóstase, dessecamento tegumentar e rigidez cadavérica. Estes ocorrem em todos os casos de morte e praticamente não dependem do modo como ocorreu o evento fatal (CAÑADAS et al, 2003).

O arrefecimento corporal, algor mortis, tem início logo que as funções vitais do corpo são cessadas, tais como os processos metabólicos e a circulação sanguínea, que mantêm a 
temperatura corporal constante em torno de $36^{\circ} \mathrm{C}$. Pelas leis da física, o corpo apresenta a tendência de atingir o equilíbrio térmico com o meio ambiente. Assim, prevê-se que o corpo humano perca em torno de $1^{\circ} \mathrm{C}$ por hora após a morte (SWIFT, 2006).

Portanto, o controlo da medição da temperatura do cadáver é um método válido para determinar o intervalo post-mortem. Geralmente, a temperatura é obtida de regiões que não estão em contato direto com o meio ambiente, como por exemplo, das axilas e da região retal. Porém, esse método, apesar de fácil e rápido, apenas se mostra confiável para as primeiras 10 horas após a morte.

A imprecisão do método de arrefecimento está relacionada com a velocidade a que se atinge o equilíbrio. Esta é uma junção de fatores muito específicos como, a temperatura ambiente, que pode oscilar bastante; a quantidade de tecido adiposo no corpo, que funciona como isolante térmico; o volume corporal total e as vestes que eventualmente cubram o corpo (DAVY, 1839).

O aparecimento de livores de hipóstases, livor mortis, e a lividez são dois fenômenos com características distintas que ocorrem ao mesmo tempo e nunca isoladamente, com uma causa em comum. Com a morte do individuo, naturalmente a circulação sanguínea é cessada e assim o sangue parado no sistema tende a acumular-se nas regiões mais baixas, mais próximas do solo, devido à ação da força gravitacional. Essas regiões vão tomar uma coloração muito intensa de tons arroxeados. Por outro lado, as regiões mais elevadas perderão o sangue e irão sofrer uma descoloração, denominada de lividez cadavérica (KNIGHT, 1996).

A lividez e a hipostase começam a surgir nas primeiras horas após a morte. Durante esses primeiros tempos, é possível verificar que pressionando o local hipostático, o sangue espalha-se, a cor desaparece e é restabelecida quase que de imediato ao cessar a pressão. Quando o IPM é maior, cerca de 6 a 15 horas, a pressão feita nessas zonas já não irá resultar no mesmo efeito, pois os livores estarão fixados. Com exceção dos casos em que existem hemorragias e das mortes por asfixia, as regiões hipostáticas estão bem visíveis.

A rigidez cadavérica, rigor mortis, é um dos últimos fenômenos cadavéricos de curta duração. Tem início de 2 a 4 horas após a morte e apresenta duração média de 12 e 24 horas até que se dê o inicio aos fenômenos de putrefação (KNIGHT, 1996).

A causa da rigidez dos músculos deriva da falta de energia metabólica na céula, pois com a presença de ATP (trifosfato de adenosina), a interação entre a actina e a miosina mantêm a musculatura relaxada. No entanto, a rigidez cadavérica pode ainda ser afetada por outros fatores, tais como, um choque emocional no momento que antecedeu a morte, 
resultando em precipitação deste fenômeno, ou então, pelo contrário, se o indivíduo estava realizando algum exercício físico antes de morrer, o que poderá atrasar essa rigidez.

Tal como acontece com todos os fenômenos cadavéricos, a rigidez é também dependente de influências climáticas. Por exemplo, quando um cadáver se encontra num ambiente com temperatura e umidade elevadas o fenômeno irá ocorrer mais tardiamente do que num cadáver mantido a temperaturas baixas (KNIGHT, 1996).

Com o final da rigidez cadavérica, surge o dessecamento tegumentar advindo do fenômeno de relaxamento e flacidez tecidual que tem início entre as 12 e 18 horas após a morte. Nesta fase é possível observar que, ao se fazer pressão nos tecidos, estes não vão retornar à forma anterior.

Para além destes fenômenos, existem ainda outras alterações no organismo capazes de fornecerem uma data aproximada da morte.

É possível aferir o IPM pelos níveis de potássio no humor vítreo. É sabido que a quantidade de potássio aumenta, progressivamente, à medida que transcorre o tempo após a morte (GARRIDO e RODRIGUES, 2014), sendo que os valores progressivos são confiáveis para os climas quentes, apenas para as primeiras 12 horas posteriores ao óbito. Por outro lado, em climas frios, a precisão pode estender-se por 24 horas. Assim sendo, este método não é aconselhável para ser utilizado na realidade brasileira, ou em países de clima tropical.

É ainda possível verificar outras alterações oculares nos cadáveres, tais como, dilatação pupilar, tela viscosa da córnea, segmentação da coluna sanguínea dos vasos oculares e perda da turgência dos globos oculares. Foi desenvolvida uma técnica de tonometria ocular que consiste no estabelecimento de uma correlação confiável entre a desidratação e o tempo transcorrido desde o decesso. Esta técnica é simples, rápida e de baixo custo e ainda apresenta uma margem de erro de apenas 1 hora, para avaliação feita nas 24 horas após o óbito (RUTTY, 2001).

A avaliação do conteúdo gástrico do indivíduo pode dar também alguma indicação significativa do IPM pela verificação do estado de digestão em que se encontram os alimentos. Contudo, o tempo de esvaziamento do estômago é variável, tanto pelo tipo dos alimentos ingeridos, como pelas idiossincrasias normais ou patológicas de cada pessoa.

Importa verificar as principais substâncias constituintes dos alimentos, bem como os reflexos hormonais autônomos, entre o estômago e o duodeno. Isto se torna decisivo para influenciar o tempo de permanência dos alimentos no organismo. Assim, os lipídios são os que apresentam um trânsito intestinal mais demorado e, em contrapartida, os carboidratos são 
os que apresentam permanência mais breve no organismo, sendo certo que as proteínas ocupam um lugar intermediário (GARRIDO e RODRIGUES, 2014).

Quando o conteúdo do estômago do cadáver exibe alimentos não digeridos, pode-se concluir que alguma refeição foi realizada, pelo menos, nas últimas duas horas antes do óbito. Existe um determinado conjunto de alimentos que podem ser encontrados no estômago e cujo achado serve como indício cronológico do lapso transcorrido desde a sua ingestão. Por exemplo, alimentos líquidos como a água, leite, chá ou café, permanecem no estômago do vivo até 2 horas após a ingestão. Por outro lado, alimentos mais difíceis de processar, como carne de porco e legumes podem permanecer até 5 horas no organismo. Desde que conhecidos os hábitos alimentares da vítima, como por exemplo, os seus horários de refeições, tipos de alimentos ingeridos e quantidade por refeição, os achados do conteúdo gástrico poderão auxiliar ainda mais na determinação do momento do óbito (HENSSGE et al, 2002).

\subsubsection{Fenômenos cadavéricos transformativos}

Os fenômenos cadavéricos transformativos são responsáveis por modificações da morfologia e estrutura mais profundas e duradouras do cadáver e são causados por uma intensa proliferação bacteriana. Entre os fenômenos transformativos, podem ser identificados dois tipos de alterações: os fenômenos transformativos destrutivos e os fenômenos transformativos conservativos.

Os fenômenos destrutivos vão dar origem ao decaimento da matéria orgânica através da autólise e da putrefação. Este último fenômeno destrutivo é o que ocorre mais frequentemente. Nele há desintegração das moléculas através de reações de redução e oxidação, baseadas na decomposição fermentativa de origem bacteriana (KNIGHT, 1996).

O estudo destes fenômenos levou à criação de períodos de putrefação que compreendem o período cromático (caracterizado pelo surgimento da mancha verde abdominal); o período enfisematoso (surgem enfisemas putrefativos causados pela infiltração gasosa no tecido subcutâneo); o período de liquefação (verifica-se um amolecimento dos órgãos e uma coloração vermelho-rosada devido ao desprendimento da epiderme, formando flictenas de dimensões variáveis, contendo líquido soro-hemático); e o período de redução esquelética (ocorre o desaparecimento dos tecidos, restando apenas os órgãos mais sólidos como o coração e os elementos mais resistentes tais como tecidos fibrosos, ligamentos e cartilagens, ou, em casos extremos, há esqueletização completa) (KNIGHT, 1996). 
A autólise é um processo abiótico, no entanto está enquadrado nos fenômenos transformativos destrutivos porque causa uma intensa destruição dos tecidos. Devido à morte celular somática do organismo, os diferentes conjuntos de células vão liberando enzimas que dão início ao processo de autólise, culminando na autodigestão tecidual. Além disso, a acidificação do meio celular devido à parada do metabolismo também contribui. Este processo tem início poucas horas após a morte, desde que se identificam os fenômenos cadavéricos abióticos, até ao surgimento dos fenômenos destrutivos. As primeiras células a evidenciarem a autólise são as células nervosas e as da medula da suprarrenal.

O fenômeno de maceração está também classificado entre os fenômenos cadavéricos transformativos destrutivos. Este compreende uma rápida sucessão da putrefação e tem como consequência o desprendimento dos tecidos moles. É um processo que ocorre quando o cadáver é mantido em meio líquido estagnado, sob ação de bactérias (GARRIDO e RODRIGUES, 2014).

Os fenômenos conservativos, tal como o nome sugere, permitem um atraso no processo de decomposição do cadáver e uma falsa conservação do mesmo. São causados essencialmente pelas condições ambientais e do próprio corpo e são classificados como: corificação, saponificação e mumificação (GARRIDO e RODRIGUES, 2014).

Apesar da existência de uma classificação dos diferentes tipos de fenômenos cadavéricos é de notar que estes são sempre dependentes de condições internas e externas. Cada cadáver é único e pode responder de forma diferente à transformação tendo em conta o local onde se encontram as condições ambientais a que está exposto e as circunstâncias que levaram à ocorrência do evento. As características individuais do cadáver, como a idade, a constituição física, o seu estilo de vida, a atividade que desenvolvia antes de ocorrer a morte, e existência de doenças previas, entre outros fatores também contribuem para a subjetividade da avaliação da datação do IPM. Assim, para uma melhor conclusão devem ser tidas em conta todas estas influências possíveis.

\subsubsection{Entomologia forense}

A Entomologia Forense é um ramo da ciência forense que se baseia no estudo do ciclo de vida de insetos e outros artrópodes para, entre outros feitos, determinar o intervalo postmortem. Para tanto, é estudada a sucessão ecológica dos insetos sobre a carcaça e, sobretudo, o estágio da metamorfose dos dípteros cujas larvas têm atividade necrofágica para, paralelamente, estabelecer uma cronologia da morte (HALL, 2005). 
Através da análise do ciclo de vida da(s) espécie(s) que são encontradas no cadáver, como ovo ou larva, e conhecendo-se bem o período de reprodução desses insetos é possível datar o IPM. Vários tipos de insetos instalam-se no cadáver em diferentes fases da decomposição. No entanto, dependendo do meio ambiente em que está inserido ou da forma como ocorreu a morte, a chegada dos insetos pode ser atrasada ou acelerada. Além disso, os tipos de seres vivos existentes no meio podem variar, assim como o seu desenvolvimento em função da variação da temperatura (HALL, 2005).

Sendo assim, apesar da Entomologia Forense aparecer como uma ciência separada, ela é a responsável por determinar o IPM na grande maioria dos casos. Tendo sempre em conta que o tipo de casos em que a Entomologia auxilia na datação da morte compreende aqueles em que o cadáver esteja envolvido num tipo de fauna específico, isto é, com a presença de insetos e outro tipo de artrópodes.

\subsection{Métodos Cronotanatognóticos Atuais}

Entre as novas técnicas que prometem maior precisão na determinação do IPM estão a espectroscopia de fluorescência da pele de cadáveres; modificações histológicas, especialmente da medula óssea; determinação dos níveis de nitrogênio, aminoácidos e citrato; e reação do tecido ósseo com luminol (GARRIDO e RODRIGUES, 2014).

O método da análise das alterações externas e histológicas das ossadas é mais fiável quando comparado a outros, apesar de ser menos objetivo. Os ossos dão uma ideia do intervalo de tempo após a morte tendo em conta a presença ou ausência de ligamentos e a percentagem de matéria gorda presente (SEELEY et al, 2003).

Atualmente, uma nova proposta foi referida na literatura para a determinação do IPM através da análise do decaimento do citrato no tecido ósseo cadavérico. Nesse estudo, concluiu-se que os níveis de citrato, presentes em valores constantes no tecido ósseo durante a vida, a partir do momento em que o indivíduo morre, começam a decair sendo possível então calcular a data do evento fatal (SCHWARCZ, AGUR e JANTZ, 2010). Contudo, não se tem informação sobre a cinética do decaimento em condições de altas temperatura e umidade, como na região tropical.

A reação do tecido ósseo com luminol baseia-se na reação do produto com sangue, resultando na produção de luminescência. O luminol é um composto que com a adição do peróxido de hidrogênio produz uma luz azul fluorescente que pode ser visualizada na escuridão e fotografada. Este teste é usado rotineiramente na prática forense para localizar 
vestígios hemáticos não visíveis, diluídas em até 1:5.000.000 (INTRONA, DI VELLA e CAMPOBASSO, 1999).

teste de luminol apresenta resultados interessantes quando executado em ossos, sendo sempre positivo e bastante intenso para ossos com um tempo post-mortem recente. $\mathrm{O}$ luminol é ineficaz quando utilizado em ossos antigos. Assim, existe uma correlação entre a intensidade da reação de luminol sobre os ossos e o IPM, sendo útil, sobretudo quando são recolhidos apenas fragmentos (INTRONA, DI VELLA e CAMPOBASSO, 1999).

Há também técnicas óticas, entre elas a espectroscopia de fluorescência que tem demonstrado um vasto uso na química analítica e apresenta suficiente sensibilidade e especificidade para a determinação de cancro e cáries dentárias, entre outras alterações biológicas teciduais. A maior vantagem das técnicas óticas é a possibilidade de resposta em tempo real, proporcionando uma investigação não invasiva e não destrutiva (ESTRACANHOLLI et al, 2009). Assim, existiria uma proporcionalidade direta entre o grau de fluorescência do tecido (p.e. pele do cadáver) e o IPM, tornando possível determinar de forma objetiva, rápida e precisa a data da morte (ESTRACANHOLLI et al, 2009).

O uso dos radionuclídeos para estimatimar o IPM tem sido constantemente sugerido, apesar de serem apontadas algumas limitações para esse método, nomeadamente o nível da diagênese (mudanças nos sedimentos após a deposição inicial). Além disso, o intervalço de tempo em que se aplicam está, em geral, fora do intersse das investigações mais comuns. Contudo, para a determinação do IPM, estudos pioneiros foram realizados e concluíram que para ossadas humanas com um tempo de pós-morte compreendido entre 15 e 77 anos, existe uma correlação entre os radionuclídeos ${ }^{238} \mathrm{U},{ }^{234} \mathrm{U},{ }^{210} \mathrm{PO},{ }^{210} \mathrm{~Pb}$ e o IPM. Isto faz com que o uso de alguns radionuclídeos possa ser também uma ferramenta importante em investigações, principalmente quando o cadáver encontrado já está esqueltizado (SWIFT et al, 2001).

Outra técnica proposta para determinar o IPM é o uso da técnica de electroforese em gel de célula única, também conhecida como ensaio de cometa, devido ao desenho que se forma na placa de electroforese. Este método avalia a fragmentação do DNA nuclear em consequência da morte celular. Após a morte de um indivíduo, as nucleases contidas nas células, ao longo do tempo, podem causar a degradação do DNA cromossômico em fragmentos cada vez menores. Estes fragmentos podem ser visualizados e isolados, tornandose possível medí-los e quantificá-los, relacionando com o IPM (JOHNSON e FERRIS, 2002).

Por meio da degradação do RNA, também foi desenvolvido um método que permitisse determinar o IPM. Tal como ocorre com o DNA, o decaimento do RNA é também dependente do tempo decorrido após a morte. Nesse intuito, foi realizado um estudo 
usando o RNA da polpa dentária, no qual se comparou o decaimento de um segmento de RNA mensageiro de $\beta$-actina com um outro menor e mais estável, permitindo estimar o IPM. Ao mesmo tempo que se verificavam diferenças no decaimento do RNA, alterações morfológicas foram observadas no dente, ao longo do intervalo post-mortem. Os dois testes juntos fizeram com que mais informação fosse agregada, resultando na determinação de IPM recente mais preciso, rápida e com um custo baixo (YOUNG et al, 2013).

A degradação de proteínas também é alvo de técnicas para determinar o IPM. Neste caso, foi usada Troponina I (cTnI), proteína básica de função regulatória. Para tanto, desenvolveu-se protocolo de extração eficiente para analisar o padrão de bandas da cTnI em tecido post-mortem. O método envolve a extração da proteína, separação por electroforese em gel desnaturante e visualização por western blot, com anticorpos monoclonais específicos para a proteína (SABUCEDO e FURTON, 2003).

Este estudo indicou que existe um padrão de bandas característico nos cadáveres humanos, uma relação pseudo-linear entre o percentual de degradação da cTnI e a variação do tempo desde a morte e, ainda, um padrão de bandas de degradação qualitativa para um IPM recente (0-5 dias). A técnica oferece uma série de vantagens, entre elas um padrão de degradação quantitativo, uma relação temporal semiquantitativa e uma dependência de temperatura manuseável através de métodos diretos de avaliação, usando termómetros analíticos/digitais (SABUCEDO e FURTON, 2003).

A espectroscopia de Raman é outra técnica utilizada com finalidades de datação do IPM. O método foi usado na análise da composição química de ossos enterrados. Os resultados do ensaios indicaram que as alterações químicas no osso devido às bactérias do solo são dependentes do tempo. O procedimento foi sensível para alterações ósseas ocorridas em dias. Assim, há grande potencial de aplicação da espectroscopia de Raman como método nãodestrutivo de estimativa do IPM (MCLAUGHLIN e LEDNEV, 2011).

Houve ainda uma tentativa de deduzir uma fórmula matemática capaz de determinar o IPM. Duas equações foram desenvolvidas no Tennessee (EUA): uma para decomposição em superfície e outra para decomposição em profundidade. Ambas são baseadas na temperatura, umidade e pressão parcial do oxigênio. Estas fórmulas devem ainda ser testadas em condições ambientais diferentes para que sofram um sucessivo melhoramento a fim de apurar a sua eficácia (VASS, 2011).

\section{Considerações Finais}


A determinação do IPM é necessária e possível de ser realizada em uma investigação criminal. Certamente, contribui para a diagnose diferencial do evento, auxilia na reconstrução da cena do crime e aponta o possível número de autores ao serem contrapostos a determinados alibis de suspeitos. Além disso, a corrtea datação da morte irá auxiliar na identificação do cadáver.

Contudo, de forma geral, os métodos de uso recorrente nas investigações, tais como: variação da temperatura corporal, formação de livores de hipóstase, relaxamento muscular, espasmos cadavéricos, coagulação sanguínea, carecem de ojetividade. Acrescenta-se que, estes métodos consomem muito tempo e não podem ser feitos no local (in situ), resultando em atraso na investigação e, consequentemente, menor eficiência da mesma.

Muitos outros métodos modernos vêm sendo propostos, alguns prometem a determinação em do IPM em tempo real, permitindo uma investigação não invasiva e não destrutiva. No entanto, alguns destes métodos podem não ser enquadrados para todos os casos, pois há grande dependência das condições climáticas e de muitos outros fatores externos. Cero é que ainda não foi descoberto o método ideal, capaz de determinar com absoluta precisão o IPM e que, ao mesmo tempo, seja fácil de executar e de custo accesível. Assim, no caso regiões de climas tropical, como o Brasil, a determinação do IPM deve ser feita com muito cuidado e sempre com a preocupação de ocorrerem possíveis alterações aos métodos pré-definidos por influências externas da elevada umidade e temperatura.

Após a análise dos diferentes métodos revistos pode-se concluir que cada cadáver pede um método de datação específico devido ao estado de degradação ou conservação e às condições ambientais. Especialmente nas regiões tropicai nas quais os fatores climáticos são potenciadores dos fenômenos putrefativos e de decomposição natural do cadáver. Assim, há muito por se descobrir sobre determinação do IPM sempre objetivando maior eficácia e precisão. 


\section{Referências Bibliográficas}

ARCHER, M. S. Rainfall and temperature effects on the decomposition rate of exposed neonatal remains. Science and Justice, v. 44, n. 1, p.35-41, 2004.

CAÑADAS, V., CARRO, L. e PEÑARANDA, J. Problemas tanatológicos médico-legal. In: Calabuig Gisbert JA. Medicina Legal y Toxicología., 5ª ed., Barcelona:Masson, p.194-218, 2003.

DAVY, J. Observations on the temperature of the human body after death. Londres, Smith, Elder and Company, 1839.

ESTRACANHOLLI, E.S., KURACHI, C., VICENTE, J.R., DE MENEZES, P.F.C., SILVA, O.C.E. e BAGNATO, V.S. Determination of post-mortem interval using in situ tissue optical fluorescence. Optics Express, v. 17, n. 10, p.8185-8192, 2009.

GARRIDO, R.G. e RODRIGUES, E.L. Ciência Forense: da cena do crime ao laboratório de DNA. Ed. Projeto Cultural/FAPERJ, 2014.

GREENBERG, B. e KUNICH, J. C. Entomology and the law: flies as forensic indicators. Cambridge, University Press, 2002.

HALL, R.D. Entomology and the law: Flies as forensic indicators. Journal of Medical Entomology, v. 42, n. 5, p. 922, 2005.

HENSSGE, C., KNIGHT, B., KROMPECHER, T., MADEA, B. e NOKES, L. The estimation of the time since death in the early post-mortem period. $2^{\mathrm{a}}$ ed, Londres:Arnold Publishing, p.215-225, 2002.

INTRONA, F., DI VELlA, G. e CAMPOBASSO, C.P. Determination of post-mortem interval from old skeletal remains by image analysis of luminol test results. Journal of Forensic Sciences, v. 44, n. 3, p.535-538, 1999.

JAFFE, A Guide to Pathological Evidence: For Lawyers and Police Officers, $2^{\mathrm{a}}$ ed., Toronto, Carswell Criminal Law Series, Carswell Ltd., 1983.

JOHNSON, Laura A. e FERRIS, James A.J. Analysis of post-mortem DNA degradation by single-cell gel electrophoresis. Forensic Science International, v. 126, n. 1, p.43-47, 2002.

KNIGHT, B. Forensic Pathology. 2a ed. New York, Oxford University Press, 1996.

LUCIO, J.V.P. Cambios post-mortem y data de la muerte en ambientes tropicales. Medicina Legal de Costa Rica, v. 30, n. 2, 2013.

MCLAUGHLIN,G. e LEDNEV, I.K. Potential application of Raman spectroscopy for determining burial duration of skeletal remains. Analytical and Bioanalytical Chemistry, v. 401, n. 8, p.2511-2518, 2011. 
POUNDER, D.J. Post-mortem Interval. EUA, Encyclopedia of Forensic Scienses, Elsevier, 2000.

ROSS, J.L.S. Geografia do Brasil. $4^{a}$ ed., São Paulo, Edusp, 2003.

RUTTY, G.N. The use of temperatures recorded from the external auditory canal in the estimation of the time since death. Sheffield, University of Sheffield, 2001.

SABUCEDO, A.J. e FURTON, K.G. Estimation of post-mortem interval using the protein marker cardiac troponin I. Forensic Science International, v. 134, n. 1, p.11-16, 2003.

SCHWARCZ, H., AGUR, K. e JANTZ, L.M. A new method for Determination of Postmortem interval: Citrate Content of Bone. Journal of Forensic Science, 2010.

SEELEY, R.; et al. Anatomia e Fisiologia. 6a ed, Lusociência, 2003.

SWIFT, B. Essentials of Autopsy Practice The Timing of Death. Essentials of Autopsy Practice, 2006.

SWIFT, B., LAUDER, I., BLACK, S. e NORRIS, J. An estimation of the post-mortem interval in human skeletal remains: a radionuclide and trace element approach. Forensic Science International, v. 117, n. 1-2, p.73-87, 2001.

VASS, A.A. The elusive universal post-mortem interval formula. Forensic Science International, v. 204, n. 1-3, p. 34-40, 2011.

WOELFERT, A.J.T. Introdução à Medicina Legal. 1ª ed, Canoas:ULBRA, 2003.

YOUNG, S.T., WELLS, J.D., HOBBS, G.R. e BISHOP, C.P. Estimating post-mortem interval using RNA degradation and morphological changes in tooth pulp. Forensic Science International, v. 229, n. 2013, p.163.e1-163.e6, 2013.

\footnotetext{
Universidade Católica de Petrópolis

Centro de Teologia e Humanidades

Rua Benjamin Constant, 213 - Centro - Petrópolis

Tel: (24) 2244-4000

lexhumana@ucp.br

http://seer.ucp.br/seer/index.php?journal=LexHumana

GARRIDO, Rodrigo Grazinoli; NAIA, Maria João Teixeira. CRONOTANATOGNOSE: A INFLUÊNCIA DO CLIMA TROPICAL NA DETERMINAÇÃO DO INTERVALO POST-MORTEM. Lex Humana, v. 6, n. 1, jul. 2014. ISSN $2175-0947$. Disponível em: http://seer.ucp.br/seer/index.php?journal=LexHumana\&page=article\&op=view\&path $\% 5 \mathrm{~B} \% 5 \mathrm{D}=562$. Acesso em: 01 Jul. 2014.
} 